\title{
PARN Gene Mutation
}

National Cancer Institute

\section{Source}

National Cancer Institute. PARN Gene Mutation. NCI Thesaurus. Code C152086.

A change in the nucleotide sequence of the PARN gene. 